\title{
OPINION \\ The impact of the Consumer Protection Act on pharmacists
}

\author{
K du Toit, E van Eeden
}

Karen du Toit is a pharmacist with a PhD degree in applied chemistry. She is an honorary associate professor in the Discipline of Pharmaceutical Sciences, University of KwaZulu-Natal, Durban, South Africa, and an admitted attorney. Evert van Eeden of Van Eeden Inc., Pretoria, is an attorney with a PhD degree in consumer law. He is the author of a book on consumer protection law in South Africa and also contributes to international legal journals.

Corresponding author: Kdu Toit (karen@pharmalaw.co.za)

The Consumer Protection Act of 2008 has had far-reaching consequences for suppliers of goods and services in South Africa. The implementation of the Act has important implications for all suppliers who enter into 'consumer transactions'. This article aims to stimulate awareness of the legal consequences of the Act arising from day-to-day situations occurring in the pharmacy, and to highlight the compliance obligations that the Act creates for pharmacists.

S Afr Med J 2014;104(11):738-740. DOI:10.7196/SAMJ.8488

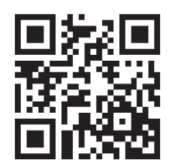

The purpose of the Consumer Protection Act $(\mathrm{CPA}),{ }^{[1]}$ in so many words, is to promote and advance the social and economic welfare of consumers in South Africa (SA). Specific protection is given to certain classes of people such as the illiterate, minors, seniors, people living in remote areas and those of low income. Most of the provisions of the Act came into effect on 1 April 2011. The provisions of the Act relating to harm caused to consumers by defective products apply only to goods supplied on or after 1 April 2011.

Interpretation of any law must promote the spirit and the objectives of the Bill of Rights, ${ }^{[2]}$ which protects the fundamental rights of every person in SA, and the CPA is no exception to this rule. For example, a pharmacist may not discriminate unfairly between patients by prioritising supply of medicines, supplying goods or services of different quality, or charging different prices to different patients on the grounds of race, gender, pregnancy, marital status, ethnic or social origin, colour, sexual orientation, age, disability, religion, conscience, belief, culture, language or birth. Furthermore, to protect his or her right to privacy the consumer may refuse to be contacted for purposes of direct marketing through electronic and postal advertising media. The consumer has a right to choose his/her supplier in that a supplier is not permitted to require, as a condition of the supply of any goods or services to a consumer, that the consumer must purchase particular goods either from that supplier or from another party. Such 'bundling' of 
goods and services is only permitted if the supplier can show that the convenience to the consumer outweighs the limitation of the consumer's right to choice, that the bundling results in economic benefit for the consumer, or that the bundled goods or services are also offered separately.

The Act should also be interpreted to give effect to its stated purposes. However, if there is inconsistency with other acts, such as the Medicines and Related Substances Act, ${ }^{[3]}$ the two acts will be applied together and inconsistencies will be dealt with by applying the provision in whichever of the acts affords greater protection to the consumer.

\section{Who are the supplier and the consumer?}

With certain exceptions, the $\mathrm{CPA}^{[1]}$ applies to all transactions entered into in SA as well as to the promotion and supply of goods and services. Pharmacies regularly advertise goods and services and enter into transactions for the supply of services such as blood pressure monitoring or goods such as medicines, and are therefore deemed to be suppliers in terms of the Act.

For the purposes of the CPA, ${ }^{[1]}$ a consumer is a 'natural person' (i.e. a human being) as well as certain 'legal persons' (typically companies). A consumer is one to whom goods or services are marketed, and/or who enters into a transaction, and/or who is the user of goods or the recipient/beneficiary of services. For purposes of the supplier's liability for harm caused by defective products (product liability), it is irrelevant whether or not the person who has been harmed was a party to the transaction in which the goods or services were procured. The result is that a supplier (including the manufacturer, an importer, a wholesaler and the pharmacy) will be liable to the 'consumer' for harm suffered as a result of defects in the product supplied, for example to a patient who has received free medication. A pharmacy may also be considered a consumer because it enters into transactions and procures medicines and other goods and services from suppliers. A pharmacy belonging to the government or that is a company and has an asset value or annual income of $\geq \mathrm{R} 2000000$ is not regarded as a consumer.

\section{Protection afforded by the CPA}

A consumer may select goods displayed in open shelves and is not responsible for loss or damage of these goods unless this results from the consumer's gross negligence, recklessness, or malicious or criminal behaviour. Generally, goods may not be displayed for sale unless their prices are also displayed. Prices may be displayed in various ways, ranging from being applied to goods to being published in relation to goods in a catalogue indicating a period during which the prices will be valid. False or misleading representations concerning the nature, advantages or price of goods or services are prohibited. The Medicines and Related Substances $\mathrm{Act}^{\left[{ }^{[3]}\right.}$ also deals with false advertisements concerning medicines.

Information in notices, documents, promotional offers and loyalty programmes must be provided in plain, understandable language, taking into account the class of consumer for whom such a document is intended. The class of consumer is determined by the literacy skill and minimum experience as a consumer of the person procuring the goods or services offered. Advantage may not be taken of consumers suffering from physical or mental disabilities, and no agreements may be made with persons lacking legal capacity, such as minors. A consumer must be provided with a written record of each transaction regarding supplied goods or services. The supplier may not enter into an agreement to supply goods/services to a consumer at unfair, unreasonable or unjust prices or terms.

Since medicines are inherently unsafe, instructions and warnings are extremely important. Information requirements in terms of labelling information, package inserts and patient information leaflets are laid down in the Regulations to the Medicines and Related Substances Act. ${ }^{[4]}$ Furthermore, staff members of a pharmacy dealing with consumers should be sufficiently trained before they are allowed to advise consumers, as is also recommended in the Good Pharmacy Practice guidelines ${ }^{[5]}$ provided by the South African Pharmacy Council.

Any consumer has the right to the good-quality service that people are generally entitled to expect. The Good Pharmacy Practice guidelines ${ }^{[5]}$ also deal with this issue and should be applied. If a pharmacy fails to supply good service, the consumer may insist on such service or ask for a reasonable refund, depending on the extent to which the pharmacy failed. Furthermore, a consumer also has the right to good-quality, safe goods without defects, which are suitable for the intended purpose and durable. In the situation where a consumer communicated the need for goods suitable for a particular purpose to the pharmacy and after delivery finds the goods unsuitable, they may be returned for a refund within 10 business days. The refund price may be reduced, for example due to consumption, but no reduction is allowed when goods are returned unopened and in the original packaging. The $\mathrm{CPA}^{[1]}$ will not apply in the above circumstances if the return of goods holds a threat to public health or is prohibited by a public regulation. The return of medicines is not prohibited by the Medicines and Related Substances Act. ${ }^{[3]}$

Unsafe and defective goods may be returned within 6 months for repair, replacement or refund without penalty under all circumstances. These returned goods can be sent back by the pharmacy to the distributors or to other entities in the supply chain if the pharmacy meets the requirements of being a consumer. This is possible because of an implied warranty of quality that is embodied in any transaction or agreement pertaining to the supply of goods to a consumer. It is also in line with the Medicines and Related Substances Act. ${ }^{[3]}$ However, if the original goods were tampered with, for example repacked in the pharmacy, return to the other entities in the distribution chain will probably not be possible. It must be noted that the Good Pharmacy Practice guidelines, ${ }^{\left[{ }^{[j}\right]}$ as well as the Regulations to the Medicines and Related Substances Act, ${ }^{[4]}$ do allow repacking if certain requirements are fulfilled. In terms of returned goods, it is clear from the Code of Conduct for Pharmacists ${ }^{[6]}$ and the Good Pharmacy Practice guidelines ${ }^{[5]}$ that medicines that have been in a patient's possession and returned must not be redispensed.

A reasonable deposit may be charged in advance for procured goods to be collected or delivered at a later date. Advance reservations, bookings or orders may be cancelled by a consumer, with the exception of special-order goods, such as medicine, that the pharmacy was required or expected to procure to satisfy the consumer's requirements and that it does not ordinarily stock. A reasonable cancellation fee may be charged depending on factors such as the nature of the goods and the length of notice, except in cases of death or hospitalisation of the consumer.

Goods must be delivered and services supplied on the date agreed upon between the pharmacist and the patient, or within a 
reasonable time, at the agreed place, as is also clear from the Good Pharmacy Practice guidelines. ${ }^{[5]}$ Goods must be delivered at the cost of the pharmacy unless expressly otherwise agreed, according to the CPA. ${ }^{[1]}$ If delivery takes place on a date or at a place not agreed upon, the consumer may require that the delivery takes place as agreed upon or cancel the agreement without penalty. The person delivering goods to the consumer must be identifiable or provide suitable identification. If goods are substituted by other goods, the transaction will apply to the substituted goods from the date of their delivery and the sales record will have to be amended.

Safety monitoring and recall of goods also forms part of the CPA. ${ }^{[1]}$ The Consumer Commission will play a role in the development of codes of practice for the investigation of defects of goods, warning of the public against these goods, and recall of goods.

\section{Liabilities and remedies}

The producer, importer, distributor and retailer of goods are all liable if the goods supplied by them were unsafe, defective or hazardous, or if inadequate instructions or warnings were provided to the consumer. They will be liable for harm in the form of death, injury, illness, loss or damage of property, or any economic loss experienced by the consumer arising therefrom. Consumers may claim from them separately or jointly. It is irrelevant whether they were negligent or not. This is often referred to as 'no-fault liability' or 'strict liability'.

Complaints of infringement of consumer rights may be lodged by any person acting on behalf of him/herself, on behalf of another person who cannot act in his/her own name, as a member of, or in the interests of, a group or class making class actions possible, or in the public interest. An association can act in the interests of its members. Consumers have a wide range of options when lodging a complaint. Complaints must first be lodged through the supplier's internal procedure where possible, with a relevant ombudsman, or in terms of an alternative dispute resolution process where this is provided for. If these processes do not result in the resolution of a dispute, a complaint can be lodged with the National Consumer Commission (NCC) to be investigated further at no cost to the consumer. In time, various industry bodies are expected to submit industry codes and ombud schemes for approval by the Minister of Trade and Industry. Once approved, a consumer will be obliged to make use of such an ombud and to await the outcome before escalating the complaint to the Commission or the courts

After investigating a dispute, the NCC may decide to issue a compliance notice or to refer the matter to the National Consumer Tribunal (NCT) or a consumer court. The Commission may also issue a notice of non-referral where complaints are frivolous or vexatious. If the matter is referred to the NCT and it is found that the consumer's rights with regard to the CPA have been contravened, an administrative fine of up to $10 \%$ of the supplier's annual turnover or R1 million, whichever is the greater amount, may be imposed. An employer of an employee who infringed a consumer's rights may be held liable separately, or jointly with the employee, for the employee's actions. A pharmacy owner will therefore be liable for infringements by staff members.

To prevent complaints from escalating and reaching the NCC and the NCT or the court, it is essential for pharmacies to deal with possible problems early. Systems should be in place to prevent infringements of consumers' rights or to detect such infringements where they do occur. Staff members should be sufficiently trained and must be able to deal with consumer complaints effectively and as soon as possible. It is also recommended that pharmacies advertise their compliance with the CPA to assure the public that they have taken the necessary action to adhere to the provisions of the Act. ${ }^{[1]}$

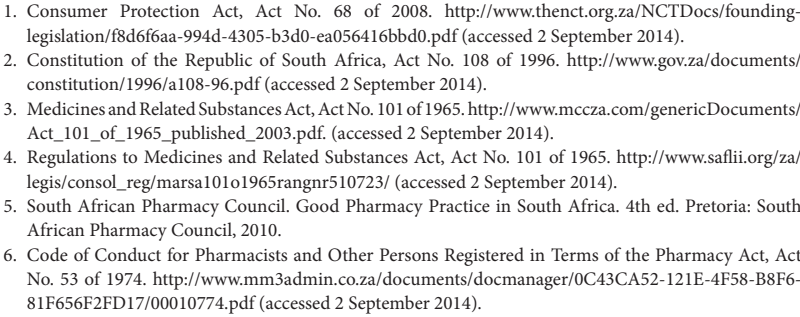

6. Code of Conduct for Pharmacists and Other Persons Registered in Terms of the Pharmacy Act, Act No. 53 of 1974. http://wwwmm3admin co za/documents/docmanager/0C43CA52-121E-4F58-B8F681F656F2FD17/00010774.pdf (accessed 2 September 2014).

Accepted 1 July 2014. 